\title{
Soil water content and temporal stability in an arid area with natural and planted grasslands
}

\author{
Ze Huang ${ }^{1,2 \S} \mid$ Hai-Tao Miao ${ }^{2 \S} \mid$ Yu Liu ${ }^{1,2} \mid$ Fu-Ping $\operatorname{Tian}^{3} \mid$ Honghua $\mathrm{He}^{2} \mid$ Weibo Shen ${ }^{2} \mid$ \\ Manuel López-Vicente ${ }^{4}$ Gao-Lin $\mathrm{Wu}^{1,2,3 *}$ \\ ${ }^{1}$ Breeding Base for State Key Laboratory of Land Degradation and Ecological Restoration of \\ North-western China / Key Laboratory for Restoration and Reconstruction of Degraded \\ Ecosystem in North-western China of Ministry of Education, Yinchuan, Ningxia 750021, \\ China \\ ${ }^{2}$ State Key Laboratory of Soil Erosion and Dryland Farming on the Loess Plateau, Northwest \\ A\&F University, Yangling, Shaanxi 712100, China \\ 3 Lanzhou Institute of Husbandry and Pharmaceutical Sciences, Chinese Academy of \\ Agricultural Sciences, Lanzhou, Gansu 730050 China \\ ${ }^{4}$ Department of Soil and Water, Experimental Station of Aula Dei, EEAD-CSIC. Avda. \\ Montañana 1005, 50059, Zaragoza, Spain \\ $\S$ These authors contributed equally to this work. \\ *Correspondence. Gao-Lin Wu.Email: gaolinwu@gmail.com; wugaolin@nwsuaf.edu.cn
}

Short running title: Soil water content in arid grasslands

Received: 2 July 2018 | Accepted: 24 September 2018 | First published: 26 September 2018 | https://onlinelibrary.wiley.com/doi/10.1002/hyp.13289

Hydrological Processes Volume 32, Issue 25, 15 December 2018, 3784-3792.

\section{Abstract}

Soil water content (SWC) is a key factor for successful vegetation restoration in arid and semi-arid regions, and vegetation has significant influences on the spatial patterns and 
temporal dynamics of SWC. The aim of this study was to investigate the temporal stability of SWC under different restored grasslands in an arid hilly area of Central China. Soil water content was measured in the $0-300 \mathrm{~cm}$ soil profile in one natural (Stipa capillata) and three typical planted (Medicago sativa, Agropyron cristatum, and Caragana korshinskii) grasslands over two growing seasons (from June to October 2015 and 2016) under natural rainfall conditions. The results showed that the mean SWC in the natural grassland was approximately $30 \%$ higher than that in the planted grasslands. The SWC-consumption of the planted legume grasslands in the deepest (below $200 \mathrm{~cm}$ ) soil layers was higher than that of the natural grassland, owing to the deep root system of the legumes. Both natural and planted grasslands had low SWC temporal stability in the top soil layers $(0-50 \mathrm{~cm})$, whereas more stable conditions were gradually observed with increasing the soil depth. The mean value of the mean relative differences (MRD) of SWC in natural grasslands (ca. 15\%) was lower than that in the planted grasslands (A. cristatum grasslands), and much lower than in the scrubland; highlighting the stronger temporal stability of SWC in the natural grasslands. In conclusion, natural grassland had higher and stable SWC and is recommended to achieve sustainable vegetation restoration in arid and semi-arid regions.

KEYWORDS: Arid areas; Gramineous grassland; Legume grassland; Soil water storage; Temporal stability.

\section{INTRODUCTION}

Land degradation is a serious ecological problem in arid and semi-arid regions (Gisladottir \& Stocking, 2005). Three of the major causes of land degradation are soil erosion, cultivation of 
marginal lands, and destruction of native vegetation (Lei et al., 2016). In the last decades, a great deal of effort has been made in restoring vegetation to control land degradation and improve the ecological indicators (Chen et al., 2007; Chen et al., 2008). Grasslands are one of the largest ecosystems in the world and play an important role in vegetation restoration (Zhang et al., 2016). Besides, recent studies have suggested that grasslands have the highest values of soil water content (SWC) in drought lands, whereas scrublands and forests present drier conditions (Zhang and Shangguan, 2016). Precipitation is the sole source of soil water replenishment in arid and semi-arid regions, and thus improper planting patterns can aggravate water scarcity and strongly influence the growth and the natural succession of vegetation (Porporato et al., 2002; Wilcox \& Newman, 2005; Shangguan \& Zheng, 2006; Chen et al., 2008; Feng et al., 2016). Restoration with improper vegetation species would accelerate the consumption of soil water, especially in arid and semi-arid regions where precipitation is generally much less than evapotranspiration (Cheng et al., 2009). Jia et al. (2017) reported that planted vegetation can aggravate soil desiccation, which threatens the success of vegetation restoration. Hence, the choice of appropriate species is a key aspect in grassland restoration plans.

The dynamics of SWC have an important effect on vegetation restoration (Wang et al., 2015), while the distribution and density of plants also influences the spatial variation of SWC (van Wesemael et al., 2003; Zucco et al., 2014). The available SWC and its distribution are affected by the interaction between the environment and plants (Wilcox \& Newman, 2005). Therefore, it is crucial to understand the spatial patterns of SWC and the temporal stability of these patterns after vegetation restoration (Zhang et al., 2016). The proper way of 
vegetation restoration appears as a non-solved question that must be based on the state of the local ecological conditions.

More than 30 years ago, Vachaud et al. (1985) first indicated that the rank of SWC changed slightly over time. Nowadays, many studies have found that the spatial patterns of SWC are stable in the medium and long term for a specific site, land use and soil and vegetation management practices (Hu et al., 2010; Zucco et al., 2014; López-Vicente et al., 2015; Zhang \& Shao, 2017; Ben-Salem et al., 2018). For instance, Xu et al. (2017) indicated that the spatial patterns of SWC in Chinese land terraces had a strong temporal stability during the rainy season. Zhao et al. (2017) recommended the use of plant species that have stronger stability and cause higher SWC for vegetation restoration. Therefore, understanding the temporal and spatial distribution of SWC is very important for successful vegetation restoration (Mcvicar et al., 2010). Wang et al. (2013) highlighted that the studies on the temporal and spatial variation of SWC in different grassland types are the basis of grassland restoration and rehabilitation in arid and semi-arid areas.

It is known that vegetation directly affects soil water inputs through precipitation partitioning by plant canopies (Marin et al., 2000). In addition, shallow-rooted plant species only influence soil water dynamics in the shallow soil layers, while species with deep roots take up water from deeper soil layers after water depletion in the shallow soil layers (Schwinning \& Sala, 2004). Therefore, transpiration is usually higher in plant communities with deep roots (Porporato et al., 2001; Moran et al., 2009).

To achieve sustainable restoration in arid and semi-arid environments, it is important to understand the relationship between vegetation patterns and SWC dynamics. Although many 
studies have analyzed the responses of soil water with different vegetation types to rainfall in arid areas (e.g. Chen et al., 2007; Wang et al., 2013), the stability of the patterns of SWC with different plant species in grasslands under natural rainfall conditions warrants further study. In this study, we firstly investigated the effects of three typical grassland species and one shrub species on the spatio-temporal dynamics of SWC in an arid region (the Chinese Loess Plateau) in the $0-300 \mathrm{~cm}$ soil profile. Secondly, the potential factors influencing on the temporal stability of SWC were evaluated. The results of this study can provide an empirical basis for designing proper grassland restoration plans in arid and semi-arid regions.

\section{STUDY AREA, METHODS, DATA, AND ANALYSIS}

\subsection{Study area}

This study was conducted at the Key Field Observation Station of the Ecological Environment of the Chinese Ministry of Agriculture $\left(36^{\circ} 01^{\prime} \mathrm{N} ; 103^{\circ} 45^{\prime} \mathrm{E}\right)$. This site is located on the Loess Plateau at an elevation of $1823 \mathrm{~m}$ a.s.l., and is part of the arid hilly and gully region. The mean annual temperature is $9.3{ }^{\circ} \mathrm{C}$, with a minimum of $-23.1{ }^{\circ} \mathrm{C}$ recorded in January, and a maximum of $39.1{ }^{\circ} \mathrm{C}$ registered in July. The annual mean precipitation is 324.5 $\mathrm{mm}$ with a humid period between July and September. The annual evaporation is approximately $1450.0 \mathrm{~mm}$. The mean annual frost-free period lasts approximately between 135 and 167 days.

The major soil type in the study area is loessial soil, and the field water capacity of the soil ranges between $19 \%$ and $23 \%$. The groundwater level is deeper than the root system of the vegetation, and thus rainfall is the sole source of soil water replenishment. There is no 
water percolating in the study area. The topography is flat and no surface runoff was observed. As reported by Bhark \& Small (2003), canopy interception loss is not obvious in grassland, and it is consumed through evaporation. Therefore, we considered that the main influencing factors on SWC were precipitation, plant consumption and evapotranspiration (Chen et al., 2008). The natural grassland ecosystem in this area is dominated by Stipa capillata Linn. Since 2002, the abandoned land has been primarily planted with three species: Caragana korshinskii Kom., Medicago sativa L. and Agropyron cristatum L.

\subsection{Field experiment and data analysis}

On the basis of the common species in the study area, three typical planted species and one natural grassland were selected, and the characteristics of the soil water variation were investigated under natural rainfall conditions (Figure 1). The planted species were Medicago sativa, Agropyron cristatum and Caragana korshinskii and plantation was done in 2002. The dominant species of the natural grassland was Stipa capillata. Medicago sativa and Caragana korshinskii are leguminous species, while Agropyron cristatum and Stipa capillata are gramineous species. The planted and natural grasslands are close together in the study area, so the differences in precipitation and other hydro-climatological factors can be ignored. 

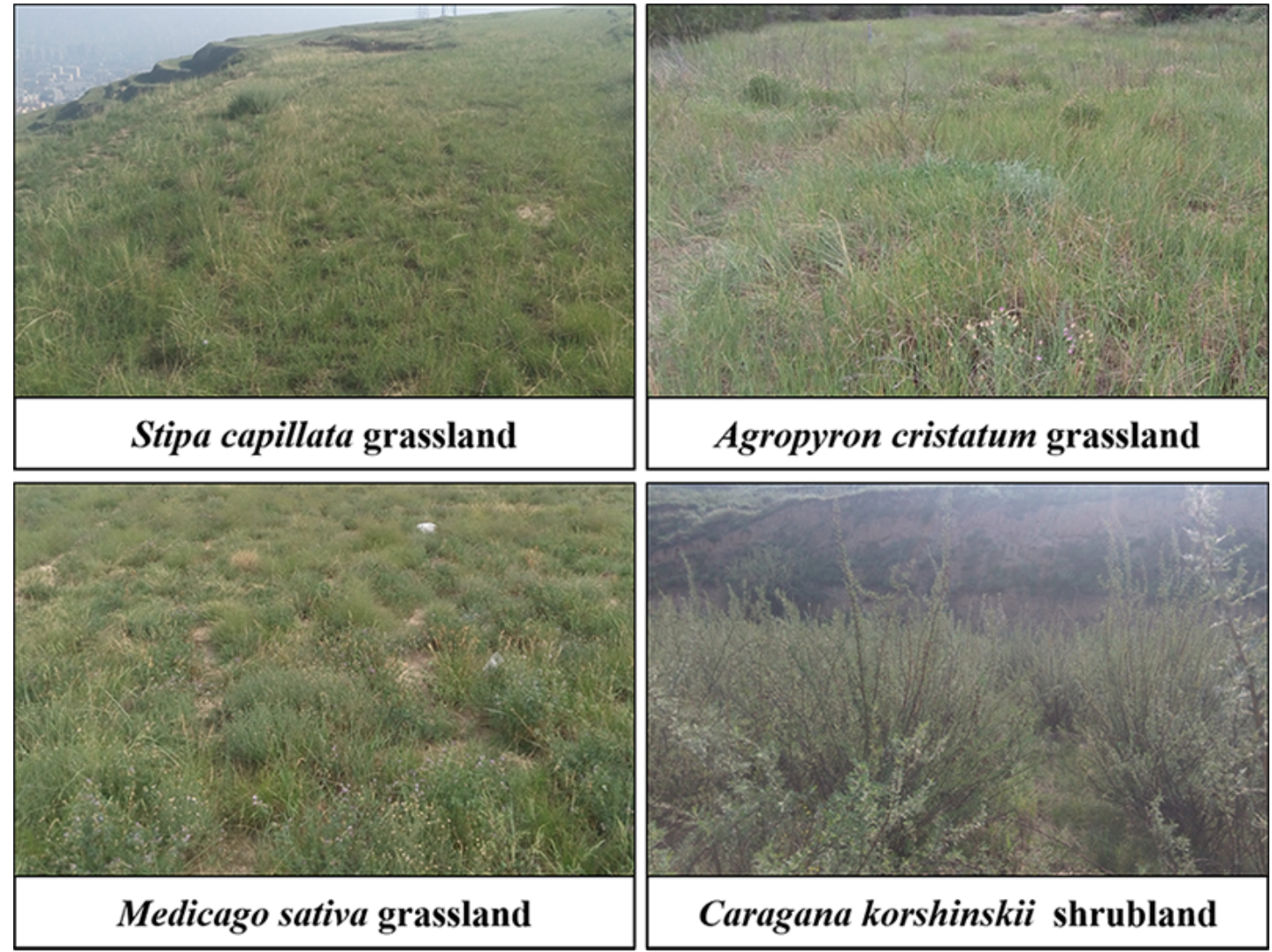

Medicago sativa grassland

Caragana korshinskii shrubland

FIGURE 1. Pictures of the studied Stipa capillata, Agropyron cristatum, and Medicago sativa grasslands and Caragana korshinskii scrubland.

The experiment was carried out from June to October 2015 and from April to October 2016. Soil water content was measured by using the soil-drilling method. Soil samples were collected in the $0-300 \mathrm{~cm}$ profile at $10-\mathrm{cm}$ intervals. For each grassland and scrubland, three parallel plots $(10 \times 10 \mathrm{~m})$ were set, and three sampling points were randomly taken from each plot, yielding a total of nine sampling point for each grassland per month (1,080 soil samples per month). All soil samples were immediately weighed after sampling collection and then reweighed after oven-drying at $105^{\circ} \mathrm{C}$ for $48 \mathrm{~h}$.

Below-ground biomass was measured by using a 9-cm diameter root auger to collect samples in the $0-100 \mathrm{~cm}$ soil profile at $10-\mathrm{cm}$ intervals. Three parallel sampling points were set at each plot, and the final sample was a mixture of the three samples from the same soil 
layer. In the laboratory, roots were separated from the soil with a 2 -mm sieve, and the separated roots were washed with water to remove soil particles and oven-dried at $75{ }^{\circ} \mathrm{C}$ for $72 \mathrm{~h}$.

The soil water steady-state infiltration rates of the different grasslands were measured using an automatic soil infiltrability measurement system (Mao et al., 2016; Wu et al., 2016b; Huang et al., 2017). Three parallel measurements were done at each grassland type. The soil bulk density for the depth of $0-100 \mathrm{~cm}$ was determined using a stainless-steel cutting ring of 5-cm diameter and 5-cm height $\left(98.2 \mathrm{~cm}^{3}\right)$. Soil bulk density below a depth of $100 \mathrm{~cm}$ was considered to be same as that at a depth of $90-100 \mathrm{~cm}$. The volumetric SWC $\left(\mathrm{cm}^{3} \mathrm{~cm}^{-3}\right)$ was calculated as follows (Gao et al., 2014):

$$
S W C=h \times \theta \times B D \times 10^{-1}
$$

where $h$ is the soil depth (cm), $\theta$ is the gravimetric soil water content (\% of weight), and $B D$ is the soil bulk density $\left(\mathrm{g} \mathrm{cm}^{-3}\right)$.

The most common method for analyzing temporal stability of SWC is based on the relative difference (RD). The analysis of $\mathrm{RD}$ can be used to estimate the positive or negative bias of soil water content during each field survey. The RD was calculated as follows (Liu \& Shao, 2014; Vachaud et al., 1985; Wang et al., 2015):

$$
R D_{i j}=\frac{S W C_{i j}-\overline{S W C_{j}}}{\overline{S W C_{j}}}
$$

where $R D_{i j}$ is the deviation of SWC at depth $i$ from the mean SWC at the sampling time $j$, $S W C_{i j}$ is the SWC at depth $i$ and the sampling time $j$, and $\overline{S W C_{j}}$ is the mean SWC of 0-300 $\mathrm{cm}$ soil profile at each grassland during the sampling time $j$. This factor was computed as follows: 


$$
\overline{S W C}_{j}=\frac{1}{n} \sum_{i=1}^{n} S W C_{i j}
$$

where $n$ is the total number of sampling layers at the sampling time $j$, and in this study $n=30$.

The mean relative difference (MRD) and its standard deviation (SDRD) at depth $i$ and sampling time $j$ were calculated as:

$$
\begin{aligned}
& M R D_{i}=\frac{1}{m} \sum_{j=1}^{m} R D_{i j} \\
& S D R D_{i}=\sqrt{\frac{1}{m-1} \sum_{j=1}^{m}\left(R D_{i j}-M R D_{i}\right)^{2}}
\end{aligned}
$$

where $m$ is the total number of sampling times. The lower the difference (positive or negative) between $S W C_{i j}$ and $\overline{S W C_{j}}$, the closer is MRD to zero value and the lower SDRD is. Low values of SDRD correspond to high temporal stability, whereas high values of SDRD are associated with low temporal variability (López-Vicente \& Álvarez, 2018; Ben-Salem et al., 2018). The statistical descriptive analyses and significance tests of differences were conducted using the SPSS 18.0 software. All figures were created using Revolution $R$ Enterprise 8.0 (Microsoft Corporation R version 3.2.2 2015) and OriginPro 2015.

\section{RESULTS}

\subsection{Rainfall characteristics}

During the observation period, the rainfall events mainly occurred from July to September in 2015 and 2016 (Figure 2). Annual precipitation in 2015 (241.5 mm) was 34\% lower than that in $2016(367.6 \mathrm{~mm})$. Most of the rainfall and daily maximum rainfall $\left(>30 \mathrm{~mm} \mathrm{day}{ }^{-1}\right)$ occurred in September 2015 and July 2016. 


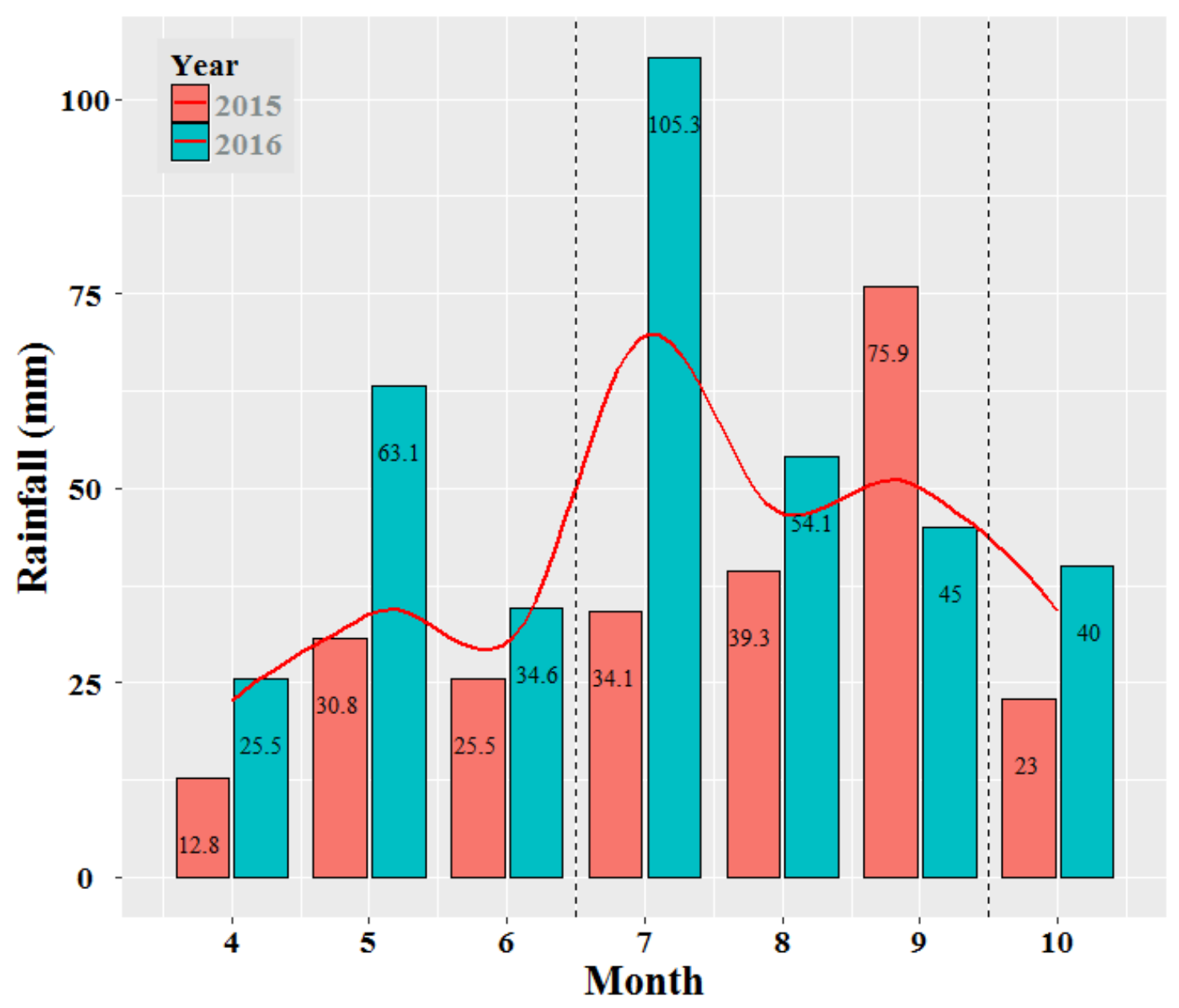

FIGURE 2. Rainfall distribution from April to October in 2015 and 2016. The red curve represented the mean value of monthly rainfall of 2015 and 2016.

\subsection{Temporal and spatial changes of SWC in the soil profile}

Lower SWC was observed in the plots with $C$. korshinskii shrubs at the depth of 0-100 cm and 200-300 cm compared with the values measured at 100-200 cm, which showed an increasing and then decreasing trend of SWC with increasing soil depth. However, SWC was lower below the $100 \mathrm{~cm}$ soil depth in the M. sativa grassland (Figure 3). Additionally, SWC was higher in A. cristatum and $S$. capillata grasslands, with relative lower values observed at the depth of $150-300 \mathrm{~cm}$ and $150-220 \mathrm{~cm}$, respectively (Figure 3). Compared with $C$. korshinskii scrubland and M. sativa grassland, SWC of A. cristatum and S. capillata 
grasslands in the top soil layer $(0-100 \mathrm{~cm})$ was higher. Moreover, in the C. korshinskii scrubland, and the M. sativa and A. cristatum grasslands, SWC below the 100-cm soil layer reached a relatively stable level (Figure 3 ). We also found that the mean SWC ( \pm standard deviation) in the $0-300 \mathrm{~cm}$ soil layers of $S$. capillata grassland $\left(6.37 \pm 1.09 \mathrm{~cm}^{3} \mathrm{~cm}^{-3}\right)$ was significantly higher than that in the A. cristatum grassland $\left(6.18 \pm 0.82 \mathrm{~cm}^{3} \mathrm{~cm}^{-3}\right)$, which was followed by the $C$. korshinskii scrubland $\left(5.06 \pm 0.63 \mathrm{~cm}^{3} \mathrm{~cm}^{-3}\right)$ and the $M$. sativa grassland $\left(4.95 \pm 0.72 \mathrm{~cm}^{3} \mathrm{~cm}^{-3}\right)$ (Figure 4, $\left.P<0.05\right)$.

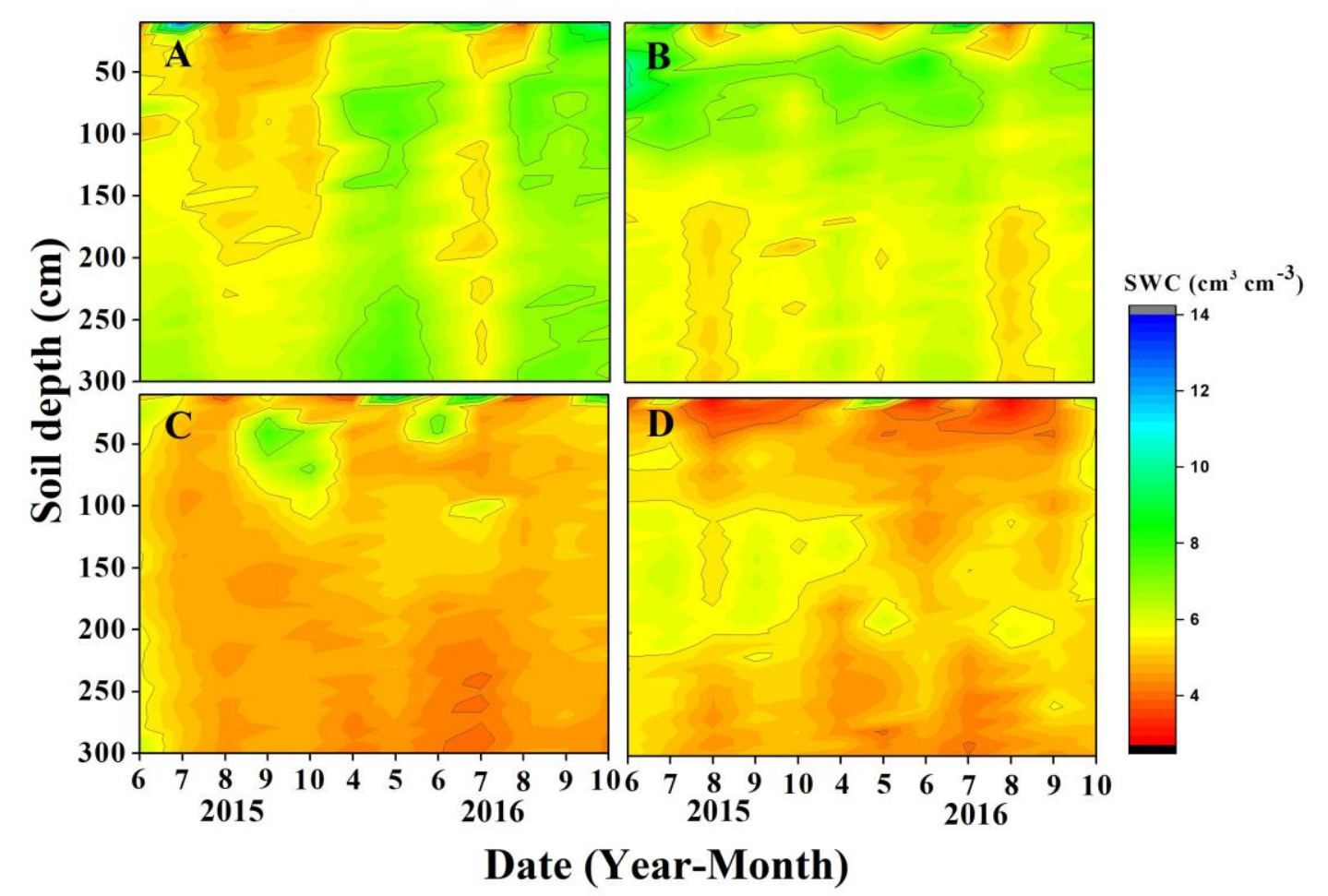

FIGURE 3. Time series of soil water content at different soil depth in (a) Stipa capillata, (b) Agropyron cristatum, and (c) Medicago sativa grasslands and (d) Caragana korshinskii shrubland under natural rainfall conditions during the study period (from June to October 2015 and April to October 2016). 


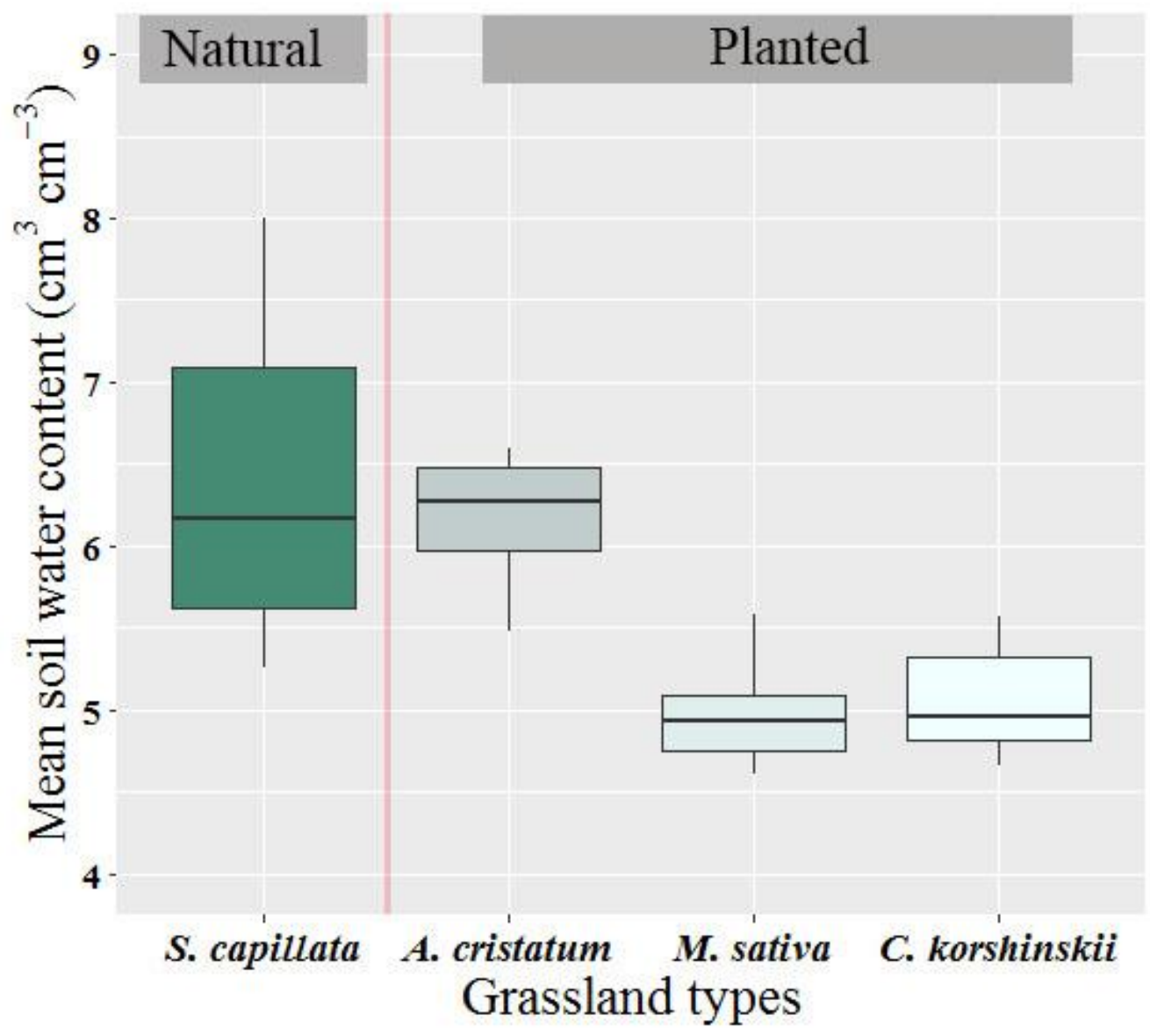

FIGURE 4. Mean soil water content within the whole study period (from June to October 2015 and April to October 2016) at different soil depth in Stipa capillata, Agropyron cristatum, and Medicago sativa grasslands and Caragana korshinskii scrubland. S. capillata grassland was natural grassland, whereas A. cristatum and $M$. sativa grasslands and $C$. korshinskii scrubland were artificially planted. Different lower case letters below the bars indicate significant differences between grassland types at the 0.05 level.

\subsection{The temporal stability of SWC}

The variation range of MRD was $-22-10 \%$ in the $C$. korshinskii scrubland, $-8-5 \%$ in the $M$. sativa grassland, $-10-21 \%$ in the A. cristatum grassland, and $-11-9 \%$ in the S. capillata grassland. The mean MRD were $1.64 \%, 0.39 \%, 0.44 \%$ and $0.39 \%$ in the C. korshinskii scrubland, M. sativa, A. cristatum and S. capillata grasslands, respectively. Among them, soil 
water content of $M$. sativa and $S$. capillata grasslands showed better temporal stability than the others. Additionally, the MRD was higher at the $0-40 \mathrm{~cm}$ and $110-200 \mathrm{~cm}$ depth in the $C$. korshinskii scrubland, while it decreased with increasing the soil depth in A. cristatum and $S$. capillata grasslands. Compared with the $C$. korshinskii scrubland and $M$. sativa grassland, the temporal stability of SWC was lower in the $0-50 \mathrm{~cm}$ soil layers in A. cristatum and $S$. capillata grasslands (Figure 5).

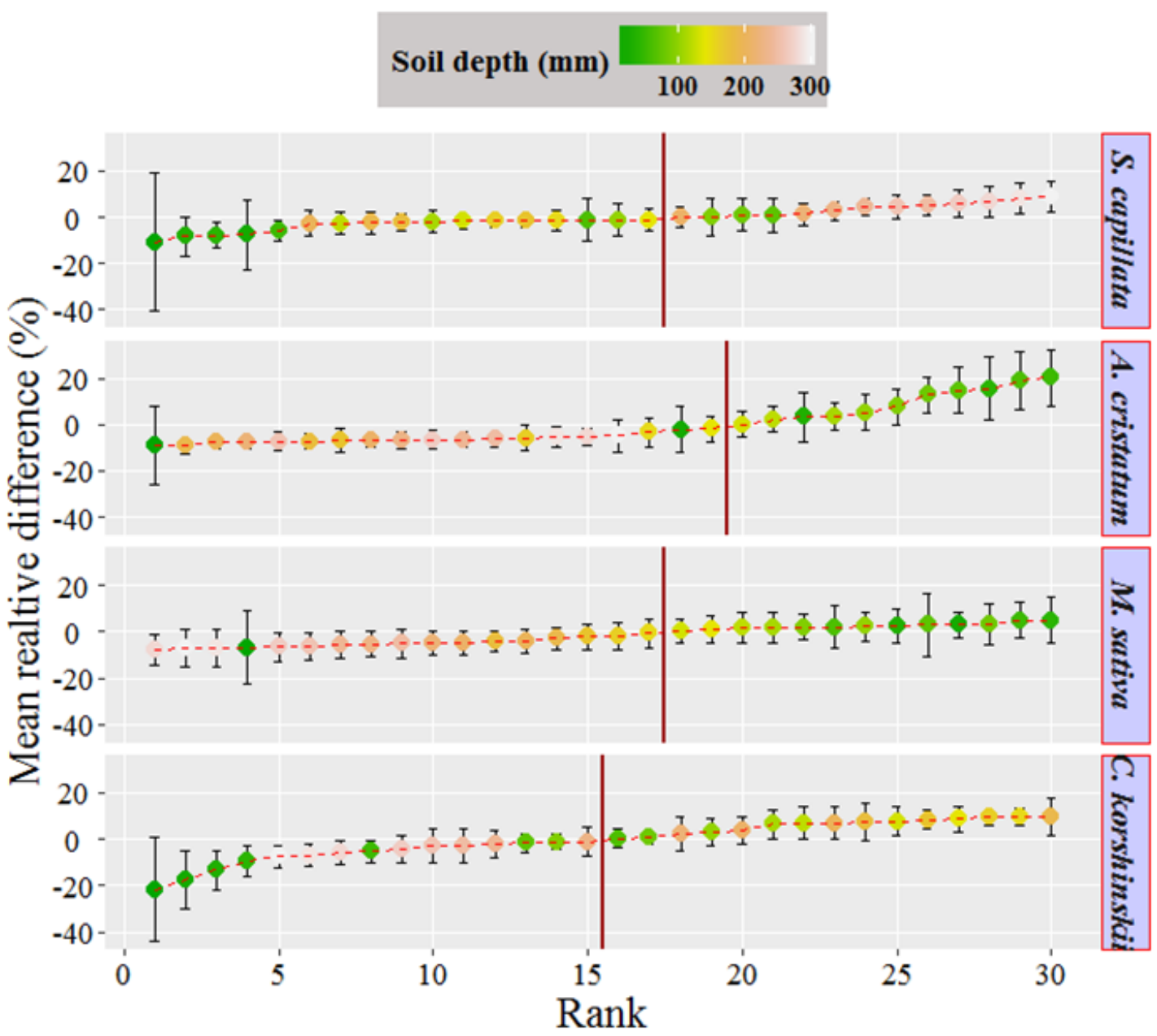

FIGURE 5. Ranked mean relative differences (MRD) of soil water content in the 0 - to 300 - $\mathrm{cm}$ soil layers in Stipa capillata, Agropyron cristatum, and Medicago sativa grasslands and Caragana korshinskii scrubland. Error bars were the standard deviation of relative difference (SDRD). The closer to zero values of MRD and lower SDRD indicate the stronger temporal stability of soil water content. 


\subsection{Below-ground biomass distribution and infiltration rates}

Below-ground biomass distributions of all grasslands and scrubland markedly decreased with increasing soil depth, with significant differences among the different grassland types (Figure 6, $P<0.05)$. Below-ground biomass of $M$. sativa grassland and $C$. korshinskii scrubland was mainly distributed in the $0-60 \mathrm{~cm}$ soil layers, whereas in the A. cristatum and $S$. capillata grasslands was mainly distributed in the $0-30 \mathrm{~cm}$ soil layers. Moreover, approximately $80 \%$ of the total below-ground biomass appeared in the $0-100 \mathrm{~cm}$ soil layers in the different grasslands. There was significantly more below-ground biomass in the M. sativa, A. cristatum grasslands and the C. korshinskii scrubland than in the S. capillata grassland at a depth of $50-80 \mathrm{~cm}$ (Figure 6, $P<0.05$ ). 


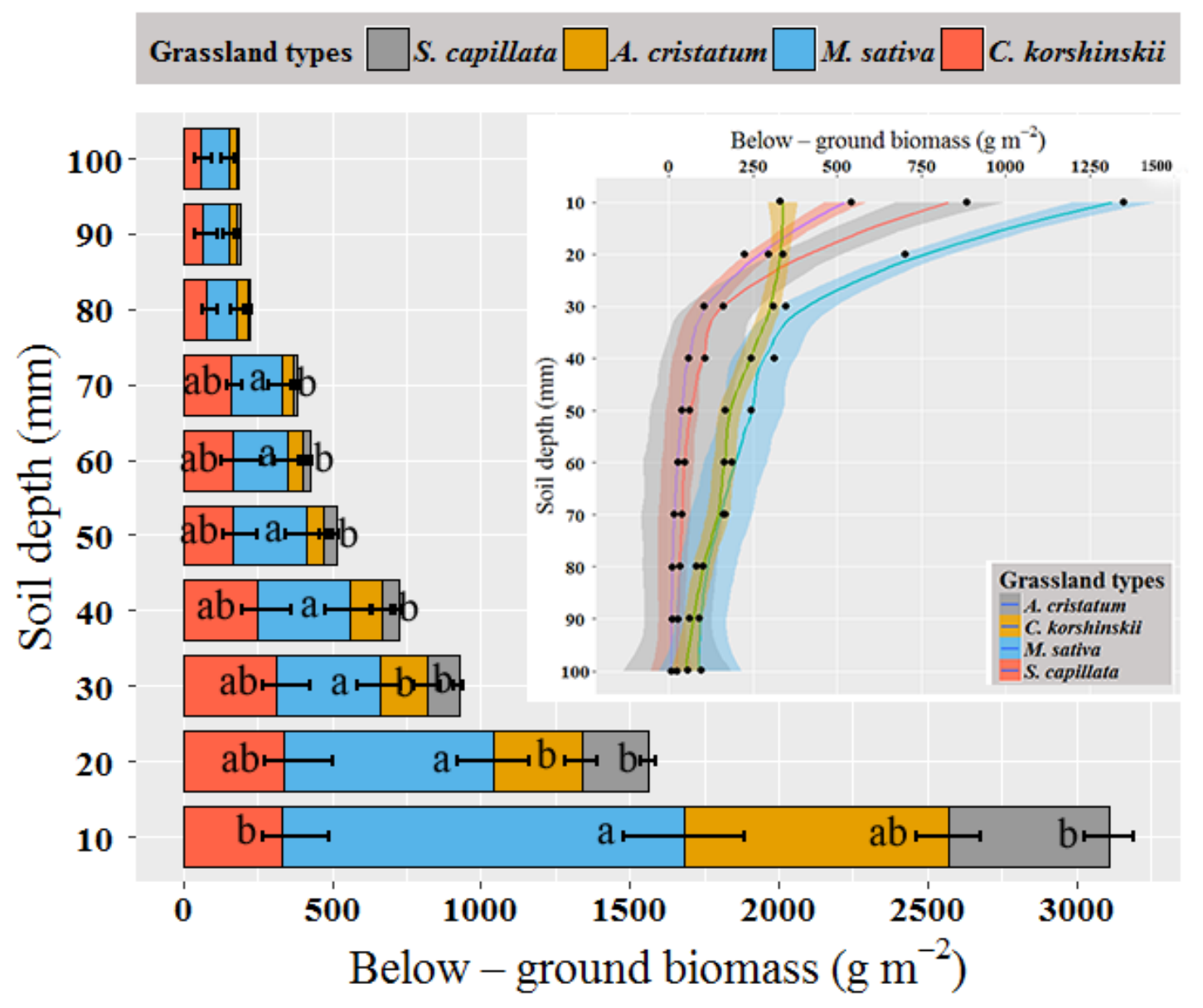

FIGURE 6. The distribution of below - ground biomass (BGB) within the 0 - to $100-\mathrm{cm}$ soil layer of Stipa capillata, Agropyron cristatum, and Medicago sativa grasslands and Caragana korshinskii scrubland. Data are presented as (a) mean \pm SD. Values followed by different lower case letters at the same soil depth in different grasslands are significantly different at the 0.05 level (LSD). The figure in the right corner showed the variation of BGB in different grassland types, and the shadow was the confidence interval.

The steady-state infiltration rate in the $M$. sativa grassland $\left(28.67 \pm 6.90 \mathrm{~mm} \mathrm{~h}^{-1}\right)$ was significantly higher than that in the $S$. capillata grassland $\left(16.60 \pm 1.11 \mathrm{~mm} \mathrm{~h}^{-1}\right.$ ) (Figure $7, P$ < 0.05). The infiltration rates in the A. cristatum grassland $\left(20.27 \pm 4.24 \mathrm{~mm} \mathrm{~h}^{-1}\right)$ and the $C$. korshinskii scrubland $\left(21.00 \pm 2.42 \mathrm{~mm} \mathrm{~h}^{-1}\right)$ were approximately $20 \%$ lower than that in the M. sativa grassland, but there was no significant difference in the infiltration rate between the 
A. cristatum grassland and the C. korshinskii scrubland.

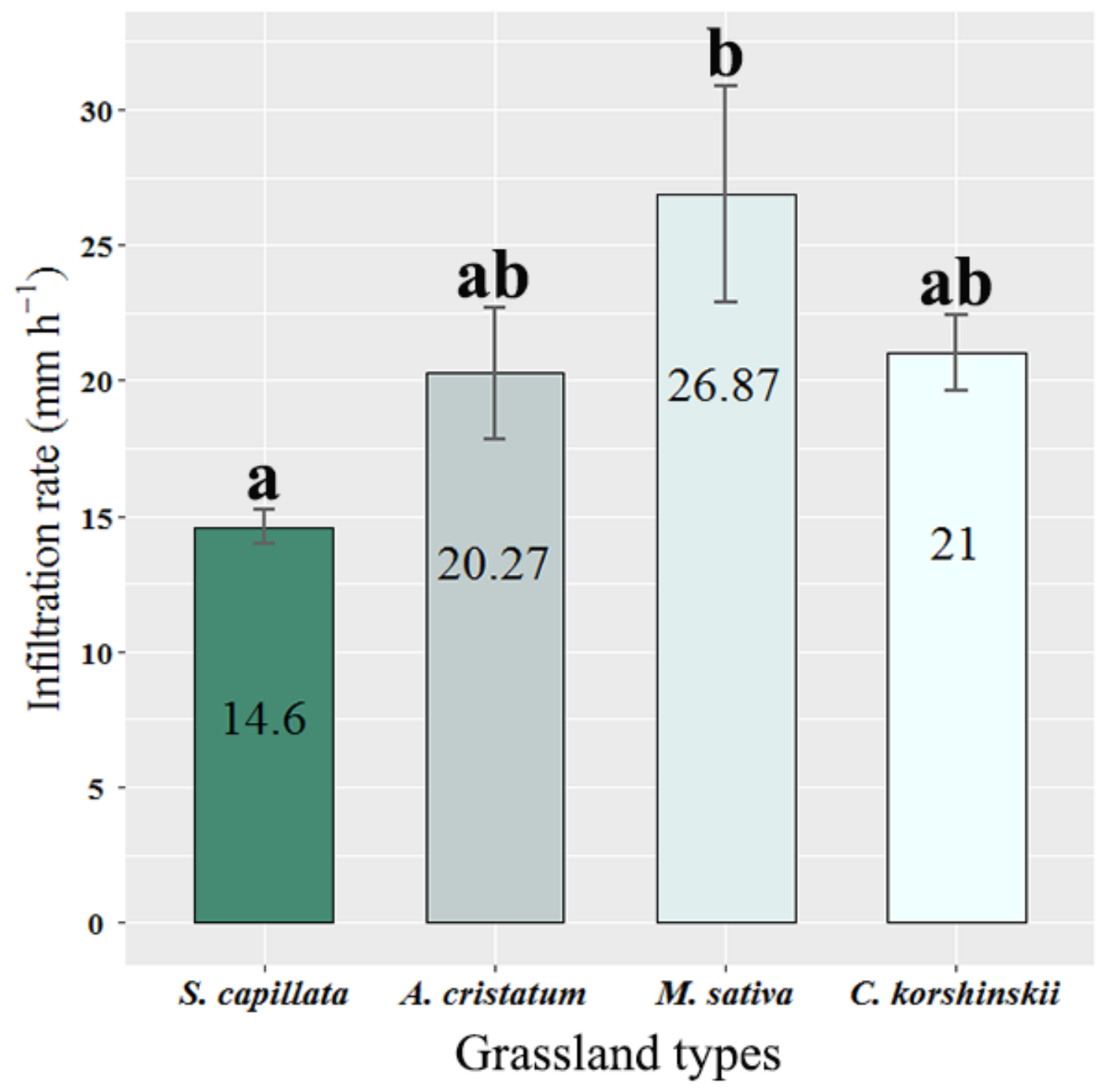

FIGURE 7. Soil steady-state infiltration rate of Stipa capillata, Stipa capillata, and Medicago sativa grasslands and Caragana korshinskii scrubland. Different lower case letters above the bars indicate significant differences between grassland types at the 0.05 level (LSD).

\section{DISCUSSION}

Although precipitation was the only source of water for soil water supplementation, most of the precipitation was insignificant for significant SWC changes at long-term, because most of the rainfall was consumed by the plants, and lost by evaporation and transpiration. Effective 
rainfall events (higher than $10 \mathrm{~mm}$ ) led to different water distributions in the soil profiles with different plants and were associated with the utilization of water at different depths (Schwinning \& Sala, 2004). In this study, SWC was lower in the three planted grasslands than in the natural grassland along the soil profile, especially below the $200 \mathrm{~cm}$ soil depth. Such trend suggested that planted grasslands can transpire deeper soil water that was accessed by the root plants in comparison with the natural grassland, and such result is more obvious for the planted legume grasslands. Our results showed that the mean SWC was lower in the legume grasslands than in the gramineous grasslands and agreed with those of Jia and Shao (2013), who suggested that legume species (C. korshinskii and M. sativa grasslands) can consume more soil water from deeper soil layers owing to their deep roots distribution. A previous study has demonstrated that the rainfall infiltration was higher in the inter-spaces than beneath the canopies in the smallest events (Bhark \& Small, 2003); but this water was only stored in the top soil layers, which would be consumed rapidly by evaporation in arid and semi-arid regions (Chen et al., 2008). Thus, soil water variation is mainly influenced by transpiration and evaporation (Wilcox, 2002), and it depended upon the distribution of plant roots (Lauenroth \& Bradford, 2006). The differences in SWC and the water portion in the soil profile between the different vegetation types were mainly influenced by the root distribution and the rooting depth (Schenk \& Jackson 2002; Fu et al., 2003; Cheng et al., 2009; Yang et al., 2014a). A previous study indicated that root water uptake is related to root biomass, and thus soil water consumption would increase with greater root biomass during the summer drought (Li et al., 2010). However, legume grasslands had higher below-ground biomass than the gramineous grasslands (Wu et al., 2016a). Our study also showed that the below-ground 
biomass was mainly concentrated at a depth of $0-60 \mathrm{~cm}$ for the legume grasslands and of 0-30 $\mathrm{cm}$ for the gramineous grasslands. Because of the majority of the roots were found at such depths, there was more soil water consumption and lower SWC at these depths (Cheng et al., 2009; Fu et al., 2012).

Infiltration rates also played an important role on SWC (Cheng et al., 2009). Grasslands with higher below-ground biomass would improve the infiltration rate (Wu et al., 2016b). The steady-state infiltration rate of the natural grassland was lower than those of the planted grasslands (Huang et al., 2017). However, less precipitation weakened the advantage of artificial grasslands resulting from their higher water consumption, which led to lower SWC than that in the gramineous grasslands along the soil profile. This result was consistent with the observations of Yang et al. (2014b), who reported that introduced grasslands (M. sativa grassland and C. korshinskii scrubland) consumed more deep soil water compared to native grassland (S. bungeana dominated grassland) in semi-arid regions. Liu and Shao (2014) also found that legume grassland consumed more deep soil water than gramineous grassland. Deep-rooted plants are high water consumers that can utilize soil water from deeper soil layers, while plants with fibrous roots are relatively low water consumers (Peláez et al., 1994; Jia \& Shao, 2013; Zhao et al., 2017). Legume grassland plants with deep taproots need more water during the growing season, and tend to dry the soil and reduce water availability in arid regions (Xu et al., 2006). In contrast, gramineous grassland plants have fibrous roots and less below-ground biomass distribution in deeper soil layers, thus consuming less soil water (Ruiz-Sinoga et al., 2011; Jia \& Shao, 2013).

Our study showed that all values of MRD were lower than $30 \%$ over the test period, 
suggesting a strong temporal stability of SWC in the arid area. The studies of Jia and Shao (2013) and Wang et al. (2015) also suggested that the temporal stability of SWC became stronger under dry conditions. The values of MRD were higher in the top soil layers $(0-50$ $\mathrm{cm}$ ), because the vertical distribution of roots are concentrated in these layers, and what made soil water more sensitive to precipitation in these layers. Roots were the major factor affecting the standard deviation of the relative differences (Xu et al., 2017). Wang et al. (2015) also indicated that the SDRD of SWC was larger within the root zone $(0-30 \mathrm{~cm})$. The temporal stability of SWC became stronger with increasing soil depth, and these results were consistent with previous research studies which indicated that SWC in deeper layers were relatively stable despite the seasonal changes (Fu et al., 2003; Liu \& Shao, 2014). Compared with the planted grasslands (PG), the values of MRD were lower in the natural grassland (NG), suggesting that NG had a stronger stability of SWC. PG had deep roots and higher infiltration rates, which result in more variable SWC over the test period than in the NG. These results suggested that soil water accumulation under PG was weaker than that under $\mathrm{NG}$, in accordance with the observations of Zhao et al. (2017). As legume grasslands have relatively deeper roots can utilize more soil water than gramineous grasslands, and thus further aggravating soil water deficit, which is not conducive to the sustainability of vegetation restoration. Within the grasslands and the scrubland of this study, the natural grassland had a higher SWC and stronger temporal stability of SWC, appearing as a better choice for vegetation restoration in arid and semi-arid regions. 


\section{CONCLUSIONS}

The vertical distribution and temporal stability of SWC were statistically different among the selected grasslands and the scrubland. SWCs of PGs were significantly lower than that of the NG, especially below the $200-\mathrm{cm}$ soil depth. Planted legume grasslands consumed more soil water through the uptake of deeper soil water by deep roots. The dry conditions of the arid study area accounted for the strong temporal stability of the SWC observed during the 2-year study period. The temporal stability of SWC was weak at the 0 - to 50-cm soil depth, and more stable conditions appeared with increasing soil depth. The temporal stability of SWC was stronger in the NG than in the artificial grasslands. Therefore, NG is a more feasible choice for vegetation restoration in arid and semiarid regions.

\section{ACKNOWLEDGMENTS}

This research was funded by the National Natural Science Foundation of China (NSFC41722107, 41525003, 41390463), the West Light Foundation of the Chinese Academy of Science (XAB2015A04), the Youth Innovation Promotion Association of the Chinese Academy of Sciences (2011288), and the Youth Talent Plan Foundation of Northwest A \& F University (2452018025), and Open Project Program of Breeding Base for State Key Laboratory of Land Degradation and Ecological Restoration of North-western China/Key Laboratory for Restoration and Reconstruction of Degraded Ecosystem in North-western China of Ministry of Education (2017KF002, 2018KF05)

Funding information. National Natural Science Foundation of China, Grant/Award Numbers: NSFC41722107, 41525003 and 41390463; the West Light Foundation of the Chinese Academy of Science, Grant/Award Number: XAB2015A04; the Youth Innovation Promotion Association of the Chinese Academy of Sciences, Grant/ Award Number: 2011288; the Youth Talent Plan Foundation of Northwest A \& F University, Grant/Award Number: 2452018025; Open Project Program of Breeding Base for State Key Laboratory of Land Degradation and Ecological Restoration of North - western China/Key Laboratory for Restoration and Reconstruction of Degraded Ecosystem in North - western China of Ministry of Education, Grant/Award Numbers: 2017 KF002 and 2018KF05. 


\section{REFERENCES}

Bhark, E.W., \& Small, E.E. (2003). Association between plant canopies and the spatial patterns of infiltration in shrubland and grassland of the Chihuahuan Desert, New Mexico. Ecosystems, 6, 185-196.

Ben-Salem, N., Álvarez, S., \& López-Vicente, M. (2018). Soil and water conservation in rainfed vineyards with common sainfoin and spontaneous vegetation under different ground conditions. Water, 10 (8), article number 1058 .

Chen, L.D., Huang, Z., Gong, J., Fu, B.J., \& Huang, Y. (2007). The effect of land cover/vegetation on soil water dynamic in the hilly area of the loess plateau, China. Catena, 70, 200-208.

Chen, H.S., Shao, M.A., \& Li, Y. (2008). The characteristics of soil water cycle and water balance on steep grassland under native and simulated rainfall conditions in the Loess Plateau of China. Journal of Hydrology, 360, 242-251.

Cheng, X.R., Huang, M.B., Shao, M.A., \& Warrington, D.N. (2009). A comparison of fine root distribution and water consumption of mature Caragana korshinkii Kom grown in two soils in a semiarid region, China. Plant and Soil, 315, 149-161.

Fu, B.J., Wang, J., Chen, L.D., \& Qiu, Y. (2003). The effects of land use on soil moisture variation in the Danangou catchment of the Loess Plateau, China. Catena, 54, 197-213.

Fu, W., Huang, M.B., Gallichand, J., \& Shao, M.A. 2012. Optimization of plant coverage in relation to water balance in the Loess Plateau of China. Geoderma, 173, 134-144.

Gao, Y., Fan, J., Peng, X.P., Wang, L., \& Mi, M.X. (2014). Soil water depletion and infiltration under the typical vegetation in the water-wind erosion crisscross region. Acta Ecologica Sinica, 34, 7038-7046.

Gisladottir, G., \& Stocking, M. (2005). Land degradation control and its global environmental benefits. Land Degradation \& Development, 16, 99-112.

Hu, W., Shao, M.A., Han, F.P., Reichardt, K., \& Tan, J. (2010). Watershed scale temporal stability of soil water content. Geoderma, 158(3), 181-198.

Huang, Z., Tian, F.P., Wu, G.L., Liu, Y., \& Dang, Z.Q. (2017). Legume grasslands are in favour of promoting precipitation infiltration than gramineous grasslands in the arid regions. Land Degradation \& Development, 28, 309-316.

Jia X.X., Shao M.A., Zhu Y.J., \& Luo Y. (2017). Soil moisture decline due to afforestation across the Loess Plateau, China. Journal of Hydrology, 546, 113-122.

Jia, Y.H., \& Shao, M.A. (2013). Temporal stability of soil water storage under four types of revegetation on the northern Loess Plateau of China. Agricultural Water Management, 117, 33-42.

Lauenroth, W.K., \& Bradford, J.B. (2006). Ecohydrology and the partitioning AET between transpiration and evaporation in a semiarid steppe. Ecosystems, 9, 756-767.

Lei, T.W., Yu, X.X., Zhuang, J., \& Zhang, Q.W. (2016). Understanding hydrological and erosion processes under a changing environment. Catena, 136, 105-107.

Li, J., Zhao, C.Y., Song, Y.J., Sheng, Y., \& Zhu, H. (2010). Spatial patterns of desert annuals in relation to shrub effects on soil moisture. Journal of Vegetation Science, 21, 221-232.

Liu, B.X., \& Shao, M.A. (2014). Estimation of soil water storage using temporal stability in four land uses over 10 
years on the Loess Plateau, China. Journal of Hydrology, 517(2), 974-984.

López-Vicente, M., \& Álvarez, S. (2018). Stability and patterns of topsoil water content in rainfed vineyards, olive groves, and cereal fields under different soil and tillage conditions. Agricultural Water Management, 201, $167-176$.

López-Vicente, M., Quijano, L., \& Navas, A. (2015). Spatial patterns and stability of topsoil water content in a rainfed fallow cereal field and Calcisol-type soil. Agricultural Water Management, 161, 41-52.

Mao, L.L., Li, Y.Z., Hao, W.P., Mei, X.R., Bralts, V. F., Li, H.R., Guo, R., \& Lei, T.W. (2016). An approximate point source method for soil infiltration process measurement. Geoderma, 264, 10-16.

Marin, C.T., Bouten, W., \& Sevink, J. (2000). Gross rainfall and its partitioning into throughfall, stemflow and evaporation of intercepted water in four forest ecosystems in western Amazonia. Journal of Hydrology, 237, 40-57.

Mcvicar, T.R., Niel, T.G.V., Li, L.T., Wen, Z.M., Yang, Q.K., Li, R., \& Jiao, F. (2010). Parsimoniously modelling perennial vegetation suitability and identifying priority areas to support China's re-vegetation program in the Loess Plateau: matching model complexity to data availability. Forest Ecology and Management, 259(7), $1277-1290$.

Moran, M.S., Scott, R.L., Keefer, T.O., Emmerich, W.E., Hernandez, M., Nearing, G.S., Paige, G.S., Cosh, M.H., \& O'Neill, P.E. (2009). Partitioning evapotranspiration in semiarid grassland and shrubland ecosystems using time series of soil surface temperature. Agricultural and Forest Meteorology, 149, 59-72.

Pelaez, D.V., Distel, R.A., Boo, R.M., Elia, O.R., \& Mayor, M.D. (1994). Water relations between shrubs and grasses in semi-arid Argentina. Journal of Arid Environments, 27, 71-78.

Porporato, A., Laio, F., Ridolfi, L., \& Rodriguez-Iturbe, I. (2001). Plants in water-controlled ecosystems: active role in hydrologic processes and response to water stress: III. Vegetation water stress. Advances in Water Resources, 24, 725-744.

Porporato, A., D'odorico, P., Laio, F., Ridolfi, L., \& Rodriguez-Iturbe, I. (2002). Ecohydrology of water-controlled ecosystems. Advances in Water Resources, 25, 1335-1348.

Ruiz-Sinoga, J.D., Galeote, M.A.G., Murillo, J.F.M., \& Marín, R.G. (2011). Vegetation strategies for soil water consumption along a pluviometric gradient in southern Spain. Catena, 84, 12-20.

Schenk, H.J., \& Jackson, R.B. (2002). Rooting depths, lateral root spreads and below-ground/above-ground allometries of plants in water-limited ecosystems. Journal of Ecology, 90, 480-494.

Schwinning, S., \& Sala, O.E. (2004). Hierarchy of responses to resource pulses in arid and semi-arid ecosystems. Oecologia, 141, 211-220.

Shangguan, Z.P., \& Zheng, S.X. (2006). Ecological properties of soil water and effects on forest vegetation in the Loess Plateau. International Journal of Sustainable Development and World Ecology, 13, 307-314.

Vachaud, G., Silans, A.P.D., Balabanis, P., \& Vauclin, M. (1985). Temporal stability of spatially measured soil water probability density function. Soil Science Society of America Journal, 49(4), 822-828.

van Wesemael, B., Cammeraat, E., Mulligan, M., \& Burke, S. (2003). The impact of soil properties and topography on drought vulnerability of rainfed cropping systems in southern Spain. Agriculture, Ecosystems \& Environment, 94(1), 1-15.

Wang, S., Fu, B.J., Gao, G.Y., Liu, Y., \& Zhou, J. (2013). Responses of soil moisture in different land cover types 
to rainfall events in a re-vegetation catchment area of the Loess Plateau, China. Catena, 101, 122-128.

Wang, T.J., Wedin, D.A., Franz, T.E., \& Hiller, J. (2015). Effect of vegetation on the temporal stability of soil moisture in grass-stabilized semi-arid sand dunes. Journal of Hydrology, 521, 447-459.

Wilcox, B.P. (2002). Shrub control and streamflow on rangelands: a process based viewpoint. Journal of Range Management, 55, 318-326.

Wilcox, B.P., \& Newman, B.D. (2005). Ecohydrology of semiarid landscapes. Ecology, 86, 275-276.

Wu, G.L., Liu, Y., Tian, F.P., \& Shi, Z.H. (2016a). Legumes functional group promotes soil organic carbon and nitrogen storage by increasing plant diversity. Land Degradation \& Development, 28, 1336-1344.

Wu, G.L., Yang, Z., Cui, Z., Liu, Y., Fang, N.F., \& Shi, Z.H. (2016b). Mixed artificial grasslands with more roots improved mine soil infiltration capacity. Journal of Hydrology, 535, 54-60.

Xu, B.C., Gichuki, P., Shan, L., \& Li, F.M. (2006). Aboveground biomass production and soil water dynamics of four leguminous forages in semiarid region, northwest China. South African Journal of Botany, 72, 507-516.

Xu, G.C., Zhang, T.G., Li, Z.B., Li, P., Cheng, Y.T., \& Cheng, S.D. (2017). Temporal and spatial characteristics of soil water content in diverse soil layers on land terraces of the Loess Plateau, China. Catena, 158, 20-29.

Yang, L., Wei, W., Chen, L.D., Chen, W.L., \& Wang, J.L. (2014a). Response of temporal variation of soil moisture to vegetation restoration in semi-arid Loess Plateau, China. Catena, 115, 123-133.

Yang, L., Chen, L.D., Wei, W., Yu, Y., \& Zhang, H.D. (2014b). Comparison of deep soil moisture in two re-vegetation watersheds in semi-arid regions. Journal of Hydrology, 513, 314-321.

Zhang, S.P., \& Shao, M.A. (2017). Temporal stability of soil moisture in an oasis of northwestern China. Hydrological Processes, 31(15), 2725-2736.

Zhang, X., Zhao, W.W., Liu, Y.X., Fang, X.N., \& Feng, Q. 2016. The relationships between grasslands and soil moisture on the Loess Plateau of China: A review. Catena, 145, 56-67.

Zhang, Y.W., \& Shangguan, Z.P. (2016). The change of soil water storage in three land use types after 10 years on the Loess Plateau. Catena, 147, 87-95.

Zhao, C.L., Jia, X.X., Zhu, Y.J., \& Shao, M.A. (2017). Long-term temporal variations of soil water content under different vegetation types in the Loess Plateau, China. Catena, 158, 55-62.

Zucco, G., Brocca, L., Moramarco, T., \& Morbidelli, R. (2014). Influence of land use on soil moisture spatial-temporal variability and monitoring. Journal of Hydrology, 516(6), 193-199. 